\title{
The Microstructure and Properties of the Coating with Vanadium Borides on Carbon Steel by Use of Electron Beam in Vacuum Treatment
}

\author{
Shun-Qi MEI ${ }^{1, a}$, Lygdenov B. ${ }^{1,2}$, Jin HUANG ${ }^{1}$, Wen-Li ZHANG ${ }^{1}$, Ya-Jie DONG ${ }^{1}$, \\ Chao LIU ${ }^{1}$, Butukhanov V. ${ }^{2}$
}

Wuhan Textile University, Wuhan, 430073, China

East Siberian State University of Technology and Management, Russian Federation

ameishunqi@vip.sina.com.

Keywords: Electron beam boronizing; Diffusion layer; Microhardness; Coatings

\begin{abstract}
Boronizing of steel surface leads to the formation of two phases $\left(\mathrm{FeB}, \mathrm{Fe}_{2} \mathrm{~B}\right)$. FeB phase has high brittleness due to its high hardness. Thus, the traditional boronizing cannot be applied for tools and machine parts, working in conditions of dynamic loads, but the new method of electronbeam heating in vacuum shows that it allows forming the coating without a fragile phase . This paper is aimed at studying on the structure and properties of coatings formed by electron beam treatment with various modes. Coatings on steel is formed from the pastes of boron carbide powder, vanadium oxide and graphite powders. Electron beam treatment in vacuum is carried out at different beam currents. It is found that the coatings based on vanadium boride can be formed at beam currents $30 \mathrm{~mA}$ and $40 \mathrm{~mA}$. Coatings consist of primary round borides and eutectic. Roundshaped crystals have the similar size. Eutectic has a lamellar structure. X-ray phase analysis shows that there is $V_{3} B_{4}$ phase. Increasing the beam current above specified values leads to intensive mixing of the paste and the steel matrix. This causes the dendrites formation on the steel surface of the iron-based alloyed with vanadium. The modes of electron beam treatment founded by this paper in a vacuum allow to form the steel surface vanadium borides with high ductility.
\end{abstract}

\section{Introduction}

Boronizing of a steel surface allows increasing durability of a machine parts, equipment and tools which are used in textile industry [1-3]. Essential defect of boride coatings obtained by traditional boriding methods is their increasing fragility. Coatings peel off during the plastic deformation with dynamic loads. It is known that boride layers consist of 2 phases: $\mathrm{FeB}$ and $\mathrm{Fe} 2 \mathrm{~B}$ [7]. FeB phase has high concentration of boron. Thus this phase has high hardness and high fragility. The problem of decreasing fragility of boride coatings can be solute in 2 ways: the developing single-phase layers with Fe2B or alloying boride layers with different elements. Previously [8-11], the authors studied single-phase boride layer alloyed by vanadium. The high-energy electron irradiation of a boronized steels was studied in works [12,13]. The structure evolution behaviors of NiAu nanospindles in oxidizing/vacuum conditions were studied in[14]. The aim of the present work is to study structure and properties of the coating with vanadium borides on carbon steel after the treatment with the use of electron beam in vacuum.

\section{Materials and Methods}

We choose carbon steel W 112 (AISI) as object of our study. The samples are coated with the paste consisting of boron carbide, vanadium oxide and graphite. The paste is applied by dipping with water as a binder. The sample is subjected to consequent electron beam irradiation in a vacuum chamber within $30 \mathrm{~s}$. The mode of exposure is following: accelerating voltage $\mathrm{V}=60 \mathrm{kV}$, electron beam current $\mathrm{I}=30-100 \mathrm{~mA}$, vacuum $-6^{*} 10^{-3} \mathrm{~Pa}$. The processing is carried out with the use of electromagnetic scan of the electron beam. The phase composition is performed by X-ray difractometer "Bruker D8" with a detector "Vantec 2000". The X-ray source is an X-ray tube 
with copper anode. X-ray spectral analysis is carried out by the electron scan microscope JSM6510 LV JEOL with microanalysis system INCA Energy 350 in the Center of collective use (ESSTU). Metallographic analysis of samples is made on a microscope "Neophot-21". Microhardness is determined on a PMT-3 tester under load $0.5 \mathrm{~N}$.

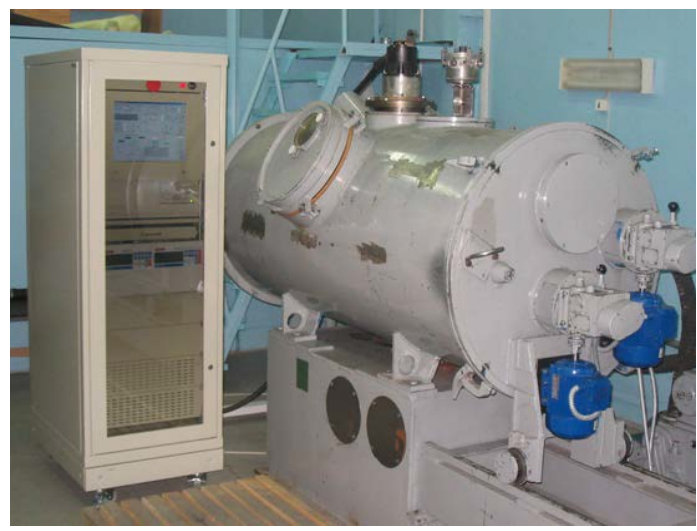

Fig. 1 The view of the electron beam setting

\section{Results and Discussion}

Figure 2 shows the microstructures of molten alloyed layers on steel W 112 after electron beam treatment by different modes. In the heat affected zones we can see coarsening of grains. The transitional zone consists of troostite and sorbite structures with microhardness of $400 \mathrm{~kg} / \mathrm{mm}^{2}$ The layers differed in their morphology and properties. The depths of the layers (h) depend on the electron beam current (I).
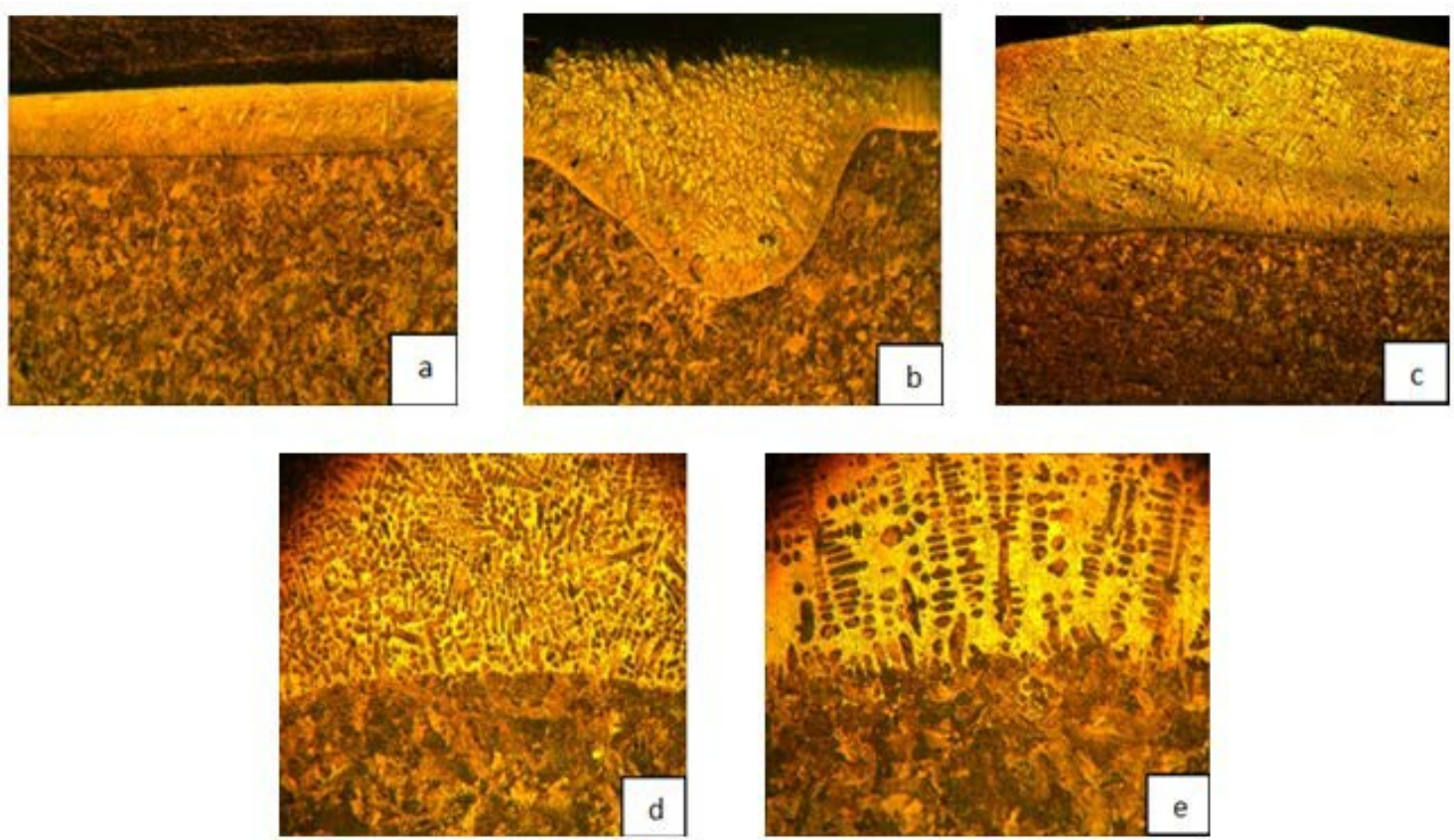

Fig. 2Microstructures of molten alloyed layers on steel W 112 after electron beam treatment by different modes: a) I=30 mA, h=160 $\mu \mathrm{m}, \times 100$; b) I=40 mA, h=630 $\mu \mathrm{m}, \times 100$; c) I=60 mA, h=100 $\mu \mathrm{m}, \times 50$; d) $\mathrm{I}=80 \mathrm{~mA}, \mathrm{~h}=1200 \mu \mathrm{m}, \times 200$; e) $\mathrm{I}=100 \mathrm{~mA}, \mathrm{~h}=1500 \mu \mathrm{m}, \times 200$

The depth of the layer after treatment mode with $\mathrm{I}=30 \mathrm{~mA}$ is $0.16 \mathrm{~mm}$, after treatment mode with $\mathrm{I}=40 \mathrm{~mA}$ is $0.63 \mathrm{~mm}$. Layers consist of primary round borides and eutectic (Fig. 3). 


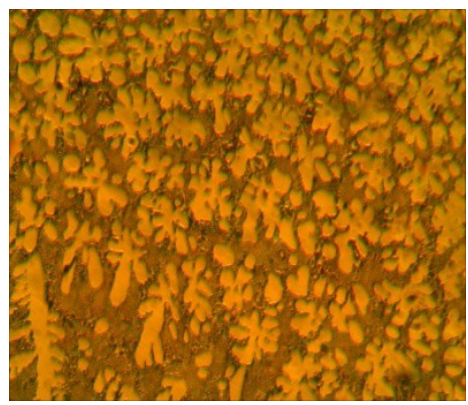

Fig. 3Microstructure of boronized zone: dendritic borides with eutectic, $\mathrm{I}=40 \mathrm{~mA}, \times 500$

Round-shaped crystals have the similar size. Eutectic has a lamellar structure. The distribution of the microhardness is presented on Fig. 4. Microhardness of the round-shaped particles is 1892 $\mathrm{kg} / \mathrm{mm}^{2}$. X-ray phase analysis showed that in layers after mode with the electron beam current $\mathrm{I}=30 \mathrm{~mA}$ and $\mathrm{I}=40 \mathrm{~mA}$ there is V3B4 phase. X-ray spectral analysis (Fig. 5) showed that there is $1,83-5,57 \mathrm{wt} . \%$ of vanadium in the eutectic, and the maimal vanadium content in the alloyed zone accounts for $69 \mathrm{wt} . \%$.

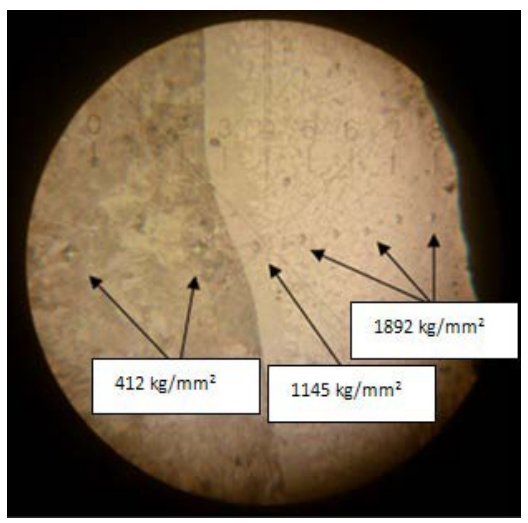

Fig. 4 Microhardness of the layer after electron beam treatment with $\mathrm{I}=40 \mathrm{~mA}, \times 400$

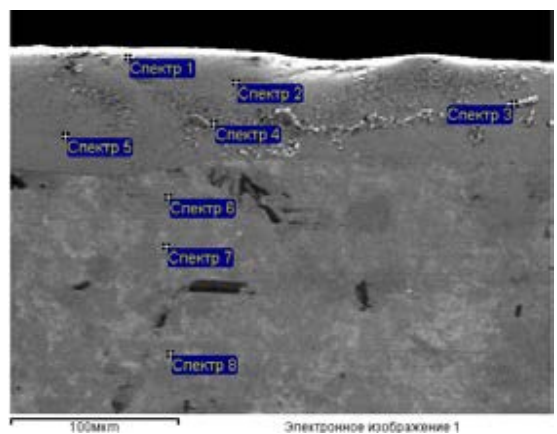

Fig. 5 Microstructure of layer with spectrum points $(\mathrm{I}=30 \mathrm{~mA})$

After processing by mode with $\mathrm{I}=60 \mathrm{~mA}$ the layer consists of smaller crystals (than in previous layers) with microhardness of $1449 \mathrm{~kg} / \mathrm{mm}^{2}$. There is a zone of eutectic under the borides. The microhardness of this zone attains $1145 \mathrm{~kg} / \mathrm{mm}^{2}$ (Fig. 7).

$\mathrm{X}$-ray spectral analysis has shown that the the content of vanadium in this layer is $14,55 \mathrm{wt} . \%$ (Fig. 8).

There are no determined vanadium borides in phase composition of the layers after the mode with $\mathrm{I}=80 \mathrm{~mA}$ and $\mathrm{I}=100 \mathrm{ma}$. This is explained by the intensive mixing of paste and metal matrix when we increase current.

The major part of those layers consists primarily of dendrites which are located in the direction 
of heat extraction (Fig. 9). The microhardness of dendrite inclusions is $473-549 \mathrm{~kg} / \mathrm{mm}^{2}$. Judging by the microhardness and the microstructure, this zone consists of ferrite alloyed with vanadium. It is known that the solubility of vanadium in $\alpha$-iron may approach from 0,9 to $1,45 \%$. X-ray spectrometry microanalysis results reveal 1,12-1,17 wt.\% vanadium content in dendrites. In eutectic zone micro-hardness is $927 \mathrm{~kg} / \mathrm{mm}^{2}$ (Fig. 10).

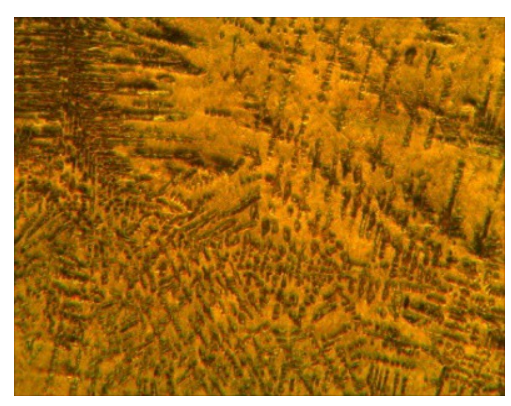

Fig. 6 Microstructures of molten alloyed layers after electron beam treatment $\mathrm{I}=60 \mathrm{~mA}$, $\mathrm{h}=100 \mu \mathrm{m}, \times 400$

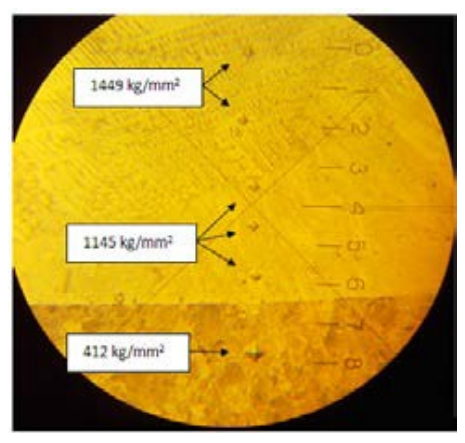

Fig. 7 Microhardness of the layer after electron beam treatment with $\mathrm{I}=60 \mathrm{~mA}, \times 400$

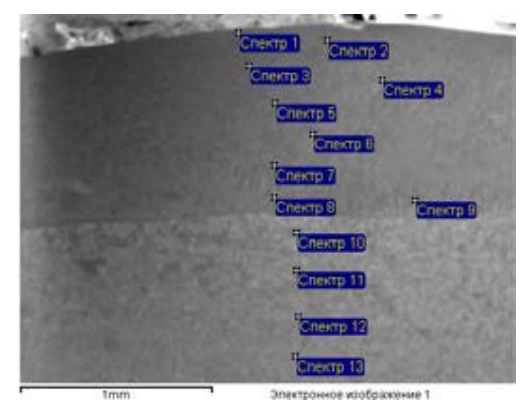

Fig. 8 Microstructure of layer with spectra points under X-ray spectrographic microanalysis (I=60 $\mathrm{mA}$ )
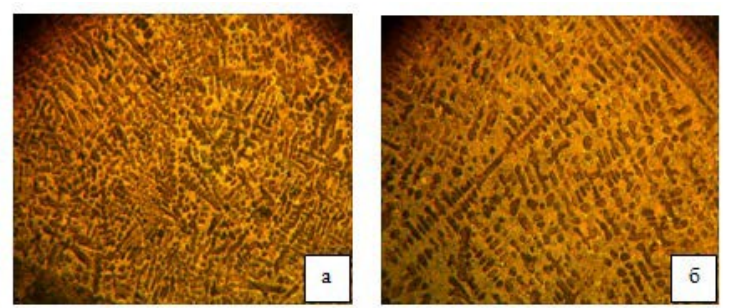

Fig. 9 Microstructures of molten alloyed layers on steel after electron beam treatment by different modes: a) I=80 mA, h=1200 $\mu \mathrm{m}, \times 200$; b) $\mathrm{I}=100 \mathrm{~mA}, \mathrm{~h}=1500 \mu \mathrm{m}, \times 200$ 


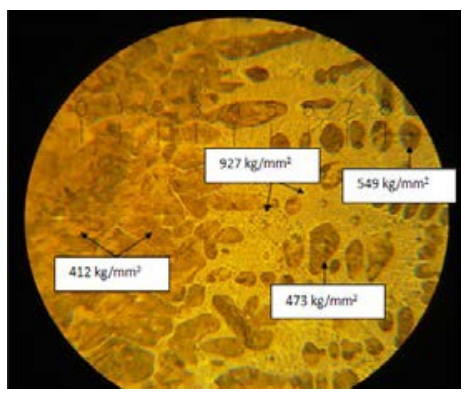

Fig. 10 Microhardness of the layer after electron beam treatment with $\mathrm{I}=100 \mathrm{~mA}, \times 400$

\section{Conclusion}

The treatment with the use of electron beam in vacuum provides simultaneous synthesis of vanadium borides on steel surface. There is significant reduction of duration of the coating formation, which shows that it has significant practical value.

Vanadium borides can be formed on steel surface according Fe-B-V diagram., and the layer thickness (depth h) varies depending on the electron beam current. This can be formed after the treatment mode with electron beam current $\mathrm{I}=30-60 \mathrm{~mA}$.

The treatment with the use of electron beam in vacuum provides a layer which is different from the layer obtained by using traditional thermochemical treatment. Needle-shaped structure of the traditional boronized layer has some significant limitations. For example, the microhardness of this layer changes stepwise.

\section{Acknowledgment}

The research work of this paper is sponsored by The Science \& Technology Research Plan of Hubei province government with project[2012AAA07-02] and [2014BHE010].

\section{References}

[1] Guryev A., Lygdenov B. , Ivanov S., Vlasova O. Kosheleva E., Guryev M., Zemlyakov S. Anew way of diffusion thermocyclic surface hardening of iron-carbon alloys // Polzunov`s Almanac.\#3, 2008. p. 10-16 (In Russian).

[2] Guryev A., Lygdenov B., Makharov D., Mosorov V., Chernykh E., Guryeva O., Ivanov S. Features of structure formation of the diffusion layer on the cast steel after thermochemical treatment // Fundamental problems of modern materials. Vol.2. \#1, 2005. p. 39-41 (In Russian).

[3] Guryev M., Filchakov D., Garmaeva I., Ivanov S., Guryev A., Okolovich G. The technology of multi-hardening coatings on steel details // Polzunov`s Vestnik. \#1, 2002. p. 73-78 (In Russian).

[4] Lygdenov B. Phase transformations in steels with a gradient structure after thermochemical and thermocyclic treatment. Thesis, Novokuznetsk, 2004 (In Russian).

[5] Guryev M., Ivanov S., Kosheleva E., Ivanov A., Greshilov A., Guryev A., Lygdenov B., Okolovich G. Complex diffusion hardening of machine parts and tools // Polzunov`s Vestnik. \#1,2010. p. 114-121 (In Russian).

[6] Lygdenov B. The intensification of the processes of structure formation of the diffusion layer on steel after chemical and heat treatment. Thesis, Barnaul, 2009 (In Russian).

[7] Butukhanov V., Lygdenov B., Garmaeva I. The use of the metallothermic method for obtaining vanadium and molybdenum // Polzunov`s Almanac. \#4, 2011. p. $72-74$ (In Russian). 
[8] Butukhanov V., Greshilov A., Lygdenov B., Omontsoo G. The study of the process of diffusion saturation in a mixture containing aluminum oxide and vanadium // Polzunov`s Vestnik. \#2, 2012. p.51-55 (In Russian).

[9] Guryev A., Kharaev Y., Guryeva O. The study of diffusion processes in the steel under cyclic thermal treatment // Modern problems of science and education. \#3, 2006. p. 65-66 (In Russian).

[10] Guryev A., Voroshnin L., Kharaev Y. Thermocyclic and thermochemical treatment of steels // Polzunov`s Vestnik. \#2, 2005. p. 36-43 (In Rusian).

[11] Lygdenov B., Kharaev Y., Greshilov A., Guryev A. Thermal cycling. Structure and properties. Moscow, 2014. p. 251 (In Russian).

[12] Sizov I., Smirnyagina N., Semenov A. Features of steel electron beam boriding. // Metallurgy and heat treatment of metals. \#12, 1999. p. 8-12 (In Russian).

[13] Krukovich M., Prusakov B., Sizov I. The ductility of boriding layers. Moscow: Fizmatlit, 2010. p. 384 (In Russian).

[14]Wei Liu,a Kai Sunb and Rongming Wang. In situ atom-resolved tracing of element diffusion in NiAu nanospindles, Nanoscale, 2013,5, 5067-5072 